\title{
EDITORS' INTRODUCTION TO THE VOLUME
}

Taxation of philanthropy is a heterogeneous topic that extends to multiple scientific disciplines. For academics and practitioners working in philanthropy, it is not uncommon to turn to branches such as philosophy, law, sociology, and economics to obtain thorough answers to the questions they encounter in their research and work. To date, however, there has been no comprehensive multidisciplinary analysis of the interaction between taxation and philanthropy. The present volume seeks to fill this gap. Through this handbook, the editors also endeavored to contribute to the emerging multidisciplinary domain that can be referred to as "the science of philanthropy." It is hoped that the readers will find the contributions in this volume not only useful but also thought provoking and that they will be encouraged to pursue such studies further.

Due to the diversity of the questions and scientific fields involved, we, the editors, have decided to structure the present handbook around four topics. The first part consolidates contributions to the justification of tax incentives for philanthropic initiatives. The second part ventures into the economic and technical aspects of tax incentives for philanthropy, exploring and comparing various models and their respective efficiencies. The third part addresses tax issues arising from cross-border philanthropy. Finally, the last part of the handbook explores the phenomena of corporate philanthropy and social entrepreneurship, inquiring into, among other things, the rationale of the traditional distinction between charity and business, which is now often blurred.

Annexed to this handbook is the OECD report "Taxation and Philanthropy," which was published in November 2020 in the context of the research project that led to this book (hereafter the "OECD report"). It is the first in-depth comparative analysis of the legal norms and practices in the field. Based on the data gathered through country questionnaires by the OECD, it provides a detailed review of the tax treatment of philanthropic entities and philanthropy as applied by 40 OECD members and participating countries. It was carried out as part of a collaboration between the OECD and the Geneva Centre for Philanthropy at the University of Geneva.

In this introduction, the contributions of all four sections of this handbook are briefly presented. 


\section{Justification of tax incentives for philanthropy}

One cannot analyze the taxation of philanthropic initiatives without addressing the fundamental question of the rationale behind the tax incentives for philanthropy. This justification raises controversies; in essence, tax incentives for private philanthropy amount to channeling public funds into support for private activities that have been decided and structured by bypassing democratic governance mechanisms. Why would legislators delegate some of their budgetary prerogatives to private actors? How can one reconcile different views on what constitutes philanthropic activity? Can a clear distinction be drawn between philanthropic and political goals? In the first part of the handbook, authors from diverse scientific fields offer perspectives on these and many other questions.

This first part of the volume opens with the contribution of Rob Atkinson, who looks at the OECD and its concept of philanthropy from a historical perspective. What was the global vision of philanthropy almost 100 years ago during the era of the Marshall Planners? Has this vision changed? Atkinson argues that philanthropy was seen as an international alliance between states, and this vision must subsist today, with activist states being the only agents of philanthropy truly capable of doing work of a global scope and scale.

Caroline Honegger, Romain Carnac, Philip Balsiger, and Alexandre Lambelet study the concept of philanthropy in Switzerland from the perspective of policymakers. After conducting and analyzing multiple interviews with politicians, they dig deep into the specific rationales and frames used by Swiss policymakers to support tax incentives for philanthropy and their understanding of the notion of public interest. These authors observe that the reasons for supporting philanthropy are diverse and sometimes contradictory due to the very different realities of philanthropy, such as the variety of types and sizes of philanthropic entities and the diversity of their goals. They suggest that when taken together and linked to discourse focused on efficiency, these arguments lead political actors to increase the incentives for philanthropy.

Emanuella Ceva's chapter offers readers a perspective on the justification of philanthropy from a political theory viewpoint. Ceva submits that members of society have reasons to be vigilant regarding and responsive to institutional failures that may threaten the general social order. When the institutional system is dysfunctional, it is justified to sustain public institutional action through donations. When such donations become crucial for proper institutional functioning, not only are they justified, but there are good reasons to incentivize them - for instance, through tax benefits. Exploring the same question from another perspective, philosopher Emma Tieffenbach analyzes the justification of tax incentives for philanthropy through the "gifting puzzle," which refers to the attempt to explain in terms of maximizing utility theory the donors' inherently costly choice to unilaterally transfer their financial resources. As Tieffenbach shows, many of the solutions offered to that puzzle amount to displacing, sometimes even erasing, the conceptual boundaries between acts of gifting and acts of consumption. Examining these solutions thus proves relevant to the actual practice of tax deductions being granted in much legislation on conditions that donations be non-profit activities of general interest.

Nicolas Duvoux offers a sociological perspective on certain aspects of taxes and giving. He delivers a qualitative study on the way philanthropic donors perceive the taxation of wealth in France. He analyzes the "elite" households that are at the top of wealth distribution and are usually considered major philanthropic donors (see also the analysis based on top income conducted by Lideikyte Huber, Pittavino, and Peter in this book). Duvoux analyzes the elite class, taking into account its diversity, and observes that the aspects of economic capital as well as occupational status, both former and current (e.g., businessmen, managers), appear to be salient in framing philanthropists' relationship with the wealth tax - for instance, in relation to 
dismissing its legitimacy. Duvoux also observes that families with larger and more dynastic wealth value tax deductions for their contribution to pluralism.

Distinguishing between charitable and political activities is often difficult, and Calum $\mathbf{M}$. Carmichael addresses this topic in his chapter. The unregulated use of private monies to finance political activities is commonly identified as constituting a risk to democracy. Carmichael seeks to clarify whether governments, in regulating the political activities that charitable organizations perform without losing their fiscal privileges, take a similarly restrictive or permissive stance as they take in regulating the private financing of politics. He finds that in all but 3 of the 16 countries that he compares, the stance toward regulating the political activities performed by charitable organizations differs from the stance toward regulating the private donations received by political entities. According to Carmichael, such inconsistencies suggest that in their regulation of charities, governments are guided by considerations apart from the use of private monies to finance political activities, and he offers examples of these.

Closing the first part of the handbook, two chapters discuss specific aspects of charitable entity exemption regimes that are potentially difficult to justify: benefits given to members and the control of the entity retained by the donor. In general, membership-based charities are almost never tax exempt, as one can also observe from the OECD report (p. 46). However, Ann O'Connell shows that the Australian legal framework diverges from this general trend because some entities that provide significant benefits to their members are recognized as charities. She explains the legal foundations of this trend and provides a critical overview. She also highlights that the Australian experience serves as a reminder to other countries of the importance of transparency and the need for ongoing vigilance in relation to eligibility for tax relief. Ian Murray examines a different aspect of the justifications of tax concessions for charitable entities. He presents a new take on different tax regulations (United States, Australia, Canada, England, and Wales), exploring the extent to which they encourage donor autonomy and control of charitable foundations' assets. Murray notes that, to the detriment of public benefit, tax laws are often overly focused on restricting marketable private benefits but not on intangible control rights, and that tax regulators generally lack the tools to reform the use of charity assets to reduce donor control. He proposes several possible reforms, such as strengthening the distinction between public and private charities, providing the tax authority with access to tools to modify a charity - such as administrative or cy-près schemes - and better support for or encouragement of charity trustees and directors to themselves access such schemes to remove donor controls.

\section{Taxes, efficiency, and donor behavior: theoretical and empirical insights}

Tax incentives in the field of philanthropy can take many forms, such as tax deductions, tax credits, tax assignments, or tax refunds to charitable organizations (Hemels, 2017: 39 et seq.;). Deduction is arguably the most-used instrument (OECD report, p. 79). The choice of approach depends on multiple factors, such as legal tradition or political motives, which do not necessarily result from an in-depth efficiency analysis. Nonetheless, the question of the efficiency of a tax incentive is a key factor in systems based on the ability to pay (Lideikyte Huber, pp. 635-638). As tax incentives for philanthropy diverge from this fundamental principle of taxation, they should, at a minimum, provide society with benefits that are larger than the concessions granted by the state to private philanthropic donors. However, it is not uncommon for states to be unclear about their objectives in this context. In addition, states do not systematically evaluate the efficiency of the incentives that they put in place (Chapter 13, Chakravarty/ 
Singh; Chapter 14, Lideikyte Huber/Pittavino/Peter). One reason for this is that the discussion regarding the efficiency of tax incentives for charitable giving (and, more generally, the efficiency of any tax incentive) is complex due, inter alia, to diverging views about the definition of efficiency. The authors in this section study various aspects of these issues, which are briefly presented in the following.

James Andreoni and Sarah Smith open this technical topic with their chapter on two issues relevant to policymakers in designing incentives for giving: tax efficiency and the social efficiency of tax incentives. They suggest that policymakers should not only focus on tax-price elasticities but also, as recent behavioral insight has shown, on the design and framing of tax incentives, including salience, fixed costs, minimum threshold, social norms, and social information. They further submit that the definition of social benefit goes beyond channeling giving to the most cost-effective charities and should also encompass discussing what it means to have a healthy charitable sector and a strong civil society. Andreoni and Smith suggest that by allowing citizens to have a say in the allocation of government funding via tax-subsidized donations, governments may help build support for tax and spending more generally.

Richard Steinberg's chapter provides a theoretical analysis that challenges several mainstream ideas frequently discussed in studies of tax incentives for philanthropy. He questions three widely reported academic findings on tax design in that context, arguing that they are wrong or misleading. He specifically argues (i) that although charitable tax deductions are, in some sense, favorable to those with higher income, they are not regressive; (ii) that the traditional treasury efficiency test is incorrect; and (iii) that the correct treasury efficiency test does not lead to social efficiency. Steinberg then discusses various policy options and trade-offs. Although the economic case for the favorable tax treatment of charitable donations is uneasy, he supports favorable tax treatment of giving, following some reforms, on noneconomic grounds.

Certain chapters in this section focus specifically on the structure and efficiency of national tax incentives that make them of particular interest to the respective countries. The contribution by Brigitte Alepin studies the Canadian tax system and concludes that it is currently inefficient. The reason for this is that the disbursement quota of foundations is too low - in other words, foundations do not spend enough annually on public utility purposes; their disbursement to society is not close to what the state currently spends on them. Therefore, this quota must be increased to make the system more efficient and justified from a policy perspective.

Maja Adena examines the treasury efficiency of German tax incentives. She analyzes German taxpayer data, alleviating the scarcity of studies on the tax-price elasticity of charitable giving behavior in European countries in comparison to numerous studies on the United States. Adena estimates the tax-price and income elasticity of charitable giving in Germany and provides evidence that donors adjust their donations gradually after changes in the tax schedule and respond to future predictable changes in price. In addition, they respond mainly to changes in current and, to a smaller extent, future income. She concludes that German tax incentives are effective overall.

Malini Chakravarty and Priyadarshini Singh provide a rare study of the Indian tax incentive regime. They argue that tax incentives in India primarily incentivize donations to government entities, and their design is conservative when compared to 11 other selected countries across the developed and developing world. Still, these authors highlight that such incentives are an important source of financial stability for smaller NGOs, which form the bulk of the sector, and a factor of recognition. On the other hand, based on analysis of available data, they also argue that such tax incentives do not cost the government much. Overall, they stress that the Indian context lacks a systematic evaluation of whether tax incentives can effectively increase donations to the non-profit sector as well as their legal and regulatory implications. 
Two chapters study national tax incentives for giving using longitudinal data. Giedre Lideikyte Huber, Marta Pittavino, and Henry Peter observe taxpayers' giving behavior in the canton of Geneva from 2001 to 2011 using tax data of the entire Geneva population. As Geneva is one of the most important cantons for philanthropic activities in Switzerland, studying taxpayers' giving patterns provides important indications about the philanthropic sector in general. The authors observe that the number of taxpayers deducting charitable donations significantly increased during the study period, and the median deduction decreased among all income classes. In other words, more taxpayers deduct charitable donations, but they deduct smaller amounts. In addition, studying the years 2001 and 2011, the authors observe that both the size and frequency of deductions for charitable donations increase sharply with taxpayers' income class.

Nicolas J. Duquette and Jennifer Mayo study the long-run distribution of philanthropy in the United States from both donor and beneficiary perspectives. They find that over several decades giving by the biggest donors increased, and those households were more likely to be married, older, and have children than households that were not top donors. The concentration of giving across charitable organizations has been more modest, suggesting that much of the concentration of donations has happened within, rather than across, charities (i.e., the charities are chaining slowly in the aggregate, but the donor base of each organization individually is becoming more top-heavy on average). Duquette and Mayo conclude with a review of tax policies that affect the composition of donors and donees as well as with proposals for tax policy reforms that would broaden the donor base.

Donor motivations play an important role in charitable giving, but do tax incentives boost them? Jo Cutler explores the psychological factors that determine donors' motivations and reviews the key findings in the fields of psychology and neuroscience. She describes the main concepts and major experimental techniques and discusses potential future research directions. Charles Sellen questions the importance of financial motivations for increasing giving. He highlights a certain fatigue in the public discourse around philanthropy, including its definition and related concepts, and suggests revitalizing it. Would placing less emphasis on the financial costs associated with giving (such as tax incentives) and instead highlighting the noneconomic benefits derived from altruism spur generosity? Sellen says yes and proposes a new paradigm centered on happiness and wellbeing, putting forth a conceptualization of philanthropy as a form of voluntary self-taxation that generates lasting inner satisfaction for the donor.

The chapter by Kimberly Scharf and Johannes Lohse pushes the boundaries of field efficiency studies, exploring questions beyond fundraising and tax incentives for giving. In particular, what motivates charities (as opposed to donors) and makes them efficient? To answer this question, Scharf and Lohse consider the implications of inter-charity competition in relation to different factors, such as the distribution of donations, charities' outputs, and the structure of charitable markets. They show that, in contrast to competition in private markets, inter-charity competition does not eliminate all inefficiencies and may even exacerbate them. They then discuss the scope of government policies and tax incentives using these insights.

What are the technical means for lawmakers to test the effects of tax incentives that have not yet been introduced in a given jurisdiction? Maja Adena highlights that the treatment of donations in tax codes and fundraising strategies, respectively, share a number of design elements. Thus, lawmakers could turn to experimental research on fundraising when looking for ways to improve tax incentives. Adena provides an overview of the experimental field literature in the economics of philanthropy, explaining what such results could suggest for tax laws and indicating research gaps. 
The section closes with an interdisciplinary study by Ursa Bernardic, Maël Lebreton, Giedre Lideikyte Huber, Henry Peter, and Giuseppe Ugazio introducing behavioral philanthropy and its relationship with tax incentives. The authors note that the behavioral philanthropy perspective and methods are particularly relevant to policymakers and law researchers who design tax-based incentives to stimulate private engagement in philanthropy. They highlight the benefits of producing data in controlled environments, such as laboratory settings. In particular, this approach promotes the understanding of the psychological and affective mechanisms supporting philanthropic decision-making, helps build new sound theories that rely on precise computational models, and provides implications for informed policy that could help design efficient tax schemes to generate the most impactful giving and welfare systems across the globe.

\section{Tax incentives for cross-border philanthropy}

Historically, tax subsidies for philanthropic activities limit tax relief for charitable donations outside national borders. There are two main reasons for this restriction. First, the driving principle is that to be justified, such relief has to produce a positive impact on the national budget, which can only happen if the receiving entity is in the same jurisdiction. In addition, cross-border philanthropic activities are more difficult to control and, therefore, potentially subject to the misallocation of funds (money laundering, terrorism funding, etc.; Silver and Buijze, 2020, p. 112). The situation is slightly different in the EU, where the European Court of Justice has issued several landmark decisions that greatly facilitate cross-border philanthropic transfers within the common market (Buijze, 2016). However, in practice, cross-border payments still encounter multiple obstacles, even in the EU, where cross-border restrictions on tax relief are still present in all jurisdictions (OECD report, p. 110). In this section, the authors outline the tax treatment of cross-border philanthropy in their respective jurisdictions as well as national and global solutions.

The opening chapter confronts the readers with the following question: Can double taxation conventions solve or alleviate the potential tax burdens of cross-border charitable giving? Xavier Oberson considers that they could indeed play a more important role in this context. Oberson bases his reasoning on various double taxation treaties, and by giving examples, he suggests new clauses that can be inserted into the treaties. For instance, the states could recognize non-profit entities as residents for convention purposes, introduce specific clauses on the deductibility of cross-border philanthropic gifts, or even in the longer term, create a multilateral approach to the problem.

Providing insight into the specific aspects of cross-border giving in the domain of art, Renate Buijze compares theory and practice, looking into the experiences of philanthropic art organizations. She concludes that, despite the relaxing of EU rules, donors face practical difficulties in cross-border giving. According to Buijze, giving intermediaries emerge as the current best solution until legislation (ideally) introduces a provision at either the national, bilateral, or supranational level that allows for tax-efficient cross-border giving to equivalent foreign philanthropic organizations based on an ex-ante approach and home country control.

Exploring cross-border philanthropy from the U.S. perspective, Eric M. Zolt poses two questions: (i) whether tax benefits should support charitable activities outside the United States and (ii) whether contributions to foreign charities should be treated differently by the U.S. tax system from contributions to domestic charities. In answering these questions, the author provides an in-depth presentation of the U.S. legal framework, showing that tax law provides relatively low barriers for U.S. donors who engage in cross-border philanthropy. The theoretical 
analysis of such a tax framework is difficult, as the United States lacks a comprehensive theory on the rationale behind tax subsidies for domestic charities engaged in domestic charitable activities. Therefore, the author discusses different factors that policymakers may find useful when considering options to either reduce or increase barriers to cross-border philanthropy.

As few countries have removed tax barriers to cross-border philanthropy, Natalie Silver's analysis of the Australian example is interesting. Silver examines the implications of Australia's shift in its policy approach from a very restrictive to a more permissive one. The chapter also assesses the lessons for other countries seeking to achieve an appropriate balance between facilitating tax-effective cross-border philanthropy and ensuring appropriate oversight of domestic entities engaged in international charitable activities.

\section{Tax incentives for hybrid entities and social entrepreneurship}

Traditionally, the legal status of a philanthropic organization, which allows it to operate under special favorable tax conditions (e.g., exempt from profit or other taxes), has stood under the assumption that such an organization does not engage in commercial activities. Over the last two decades, however, an entirely new sector that does not fit into the distinction between traditional business and charity has emerged. This new sector is usually called "social entrepreneurship" or "for-profit charity." The so-called "social enterprises" operating in this context (for instance, "hybrid entities" or "B-corporations") blur the line between the profit and non-profit sectors, as they derive revenues from commercial activities, but their main - or, in any event, substantial - objective is to have a positive social impact rather than merely to maximize their owners' profit. Certain countries (e.g., the United States and Italy) have adopted new legal forms of entities to accommodate these "hybrid" goals without granting them any tax benefits. ${ }^{1}$ Thus, social entrepreneurs may be confronted with the following dilemma: Either operate via a tax-exempt organization, without the possibility to self-finance their activities, or choose a taxable business entity and face potential difficulty finding investors to fund their socially responsible activities.

Authors from four jurisdictions - the Netherlands, the United States, Australia, and Switzerland - discuss various aspects of this emerging phenomenon.

Showing that companies and corporate foundations have become important players in philanthropy, Dutch scholar Sigrid Hemels analyzes the general business rationale driving corporate philanthropy, questioning, for instance, the distinction between sponsorship and donations. Furthermore, Hemels illustrates the challenges the Netherlands faces in trying to fit the entrepreneurial forms of philanthropy into its system for gift deductions and charities. In particular, she highlights problems in relation to the deductibility of corporate gifts, donations of shares, donations to for-profit entities, as well as program-related investments, and describes existing and potential solutions to such problems. She also highlights the threats represented by the EU Common Consolidated Corporate Tax Base (CCCTB) directive. It could harm corporate philanthropy in the Netherlands because of its interplay with the Dutch national legislation, which would, in effect, result in limiting corporate deductions.

Stephanie Koolen-Maas, Claire van Teunenbroek, and René Bekkers explore the 2012 tax reform on charitable donations in the Netherlands, which enhanced the deductibility of gifts to cultural organizations and allowed cultural organizations to earn more commercial income. The goal of the reform was to encourage the cultural sector to reduce its historical dependency on government grants, become more entrepreneurial, and increase philanthropic giving by private donors and corporations. Using survey data, the authors find that giving to culture has increased but probably not as a result of the tax reform. Among cultural nonprofit 
organizations, they observe an increase in entrepreneurial orientations but not more diversification of income. They also observe a Matthew effect, as larger cultural nonprofit organizations prove more successful in attracting other forms of income.

Addressing the same question from the U.S. perspective, Steven Dean and Dana Brakman Reiser consider why socially responsible business struggles to attract investors and what the importance of trust between philanthropists and society is. They outline the last half-century history of American philanthropy from the perspective of Stanley Surrey, highlighting that often philanthropists hope to retain access to their wealth. To re-establish trust, the authors suggest using a wealth tax that falls more lightly on assets placed in private foundations than on assets lodged in alternative vehicles that are currently popular among U.S. philanthropists, such as philanthropy LLCs. In fact, such a tax scheme may nudge elites to donate rather than burden them.

Fiona Martin analyzes the framework for social enterprises in Australia. She shows that currently, there is no separate legal structure for social enterprises in the Australian legal system, and that such enterprises are commonly operated by charities. The social enterprises may be either an income-tax exempt or for-profit company limited by shares. Martin discusses the overlap, limitations, and advantages of carrying out a social enterprise through charity and uses case studies to demonstrate the advantages and disadvantages of this approach in Australia.

Raphaël Gani then discusses the Swiss legal framework as well as the general rationale for social enterprises, focusing on the conditions under which entrepreneurial activities can claim tax exemptions. Analyzing the current tax and competition laws in Switzerland, Gani advocates for a larger exemption framework in favor of social enterprises.

In the final chapter of the handbook, Philippe Durand, Dominique Lemaistre, and Laurence de Nervaux address the French approach as to which entity and, more generally, which activity should be considered of public interest and should thus enjoy privileged tax treatment. As in other countries, the test includes whether and to what extent such entities carry out economic activities, on the one hand, and, on the other, whether competition law is complied with, both issues being intertwined. They review the development of the French requirements and argue that the current French system needs to be amended in order to take better account of the growing social impact of economic activities.

\section{The OECD 2020 Taxation and Philanthropy policy study ${ }^{2}$}

This book also contains the OECD 2020 report entitled "Taxation and Philanthropy" (hereafter "the report"), the first-ever OECD study on the tax treatment of philanthropy, issued in collaboration with the GCP. The report acknowledges that in most countries philanthropy plays an important role in mobilizing private support for the public good. Some cross-country studies estimate the economic contribution of the non-profit sector at as much as $5 \%$ of the global GDP, and this support is especially vital in times of hardship and crisis, such as during the COVID-19 pandemic. The report undertakes a detailed study of the legal frameworks related to tax incentives for the charitable sector. 40 countries took part in this survey.

The fundamental question in the report is as follows: How can governments design tax rules that support philanthropy in a manner that aligns with the public interest? An overview of related doctrines shows that striking the right balance can be difficult, as certain theoretical and practical difficulties exist with regard to the justification of such incentives. In particular, tax support for philanthropy can raise inequality and democracy concerns, as such policy measures could give a small number of wealthy donors disproportionate influence over how public resources are allocated. This apprehension is highlighted by the rise in the number of very large private philanthropic foundations established by ultra-high-net-worth individuals, who are able 
to channel substantial resources into their own priorities while significantly minimizing their tax liabilities. While risks of abuse should be addressed, this concern should not overshadow the overwhelmingly positive contributions of philanthropy in general.

Nonetheless, the report suggests that there are ways to safeguard tax systems and allow governments to continue providing support to the philanthropic sector. It highlights a number of important considerations for policymakers to help them strike a balance. First, the report suggests that policymakers should reassess the activities eligible for tax support. In particular, across the countries surveyed, the activities eligible for tax support were very broad. Countries should ensure that the range of activities eligible for tax support is limited to those areas that are consistent with their underlying policy goals. In addition, the OECD suggests the use of tax credits and fiscal caps for this purpose. The report highlights that, among the countries surveyed, the most popular tax incentive for philanthropic giving is tax deductions. However, this can disproportionately benefit higher-income taxpayers. A tax credit coupled with a percentage-based cap may be fairer and more closely aligned with democratic principles. Furthermore, reassessing the extent of tax exemptions for the commercial income of philanthropic entities could also be considered. Exempting income from commercial activities could be limited to the extent that they are related to the purpose of the entity. Taxing unrelated commercial income would minimize any competitive disadvantage faced by for-profit businesses. The report also suggests reducing the complexity of tax rules and related compliance costs that disproportionately affect low-income donors and smaller philanthropic entities. For this purpose, the countries could, for example, align the eligibility requirements for tax incentives, simplify the tax rules for non-monetary donations, and facilitate payroll schemes for philanthropic giving. Another important policy measure could be to improve the oversight of tax concessions. Increased transparency, such as public registers of approved philanthropic entities, annual reporting, differentiating between donating and sponsoring, and publishing tax expenditure data, would help safeguard public trust in the sector and ensure that tax concessions used to subsidize philanthropy are better understood by the public at large and not abused through tax avoidance and evasion schemes. Finally, the OECD report suggests reassessing restrictions imposed on cross-border philanthropic activities. Responding to global issues such as poverty, environmental concerns, and pandemics may require countries and institutions to cooperate across borders. With appropriate requirements, equivalent tax treatment can be provided to domestic and cross-border philanthropy.

As can be seen, the authors participating in this volume cover extremely diverse questions and perspectives related to taxation and philanthropy. The OECD report presents an additional in-depth comparative study on this topic. A number of the issues and problems raised remain open for further analysis and potential solutions, as not all contributions provide final answers. However, we believe that these works offer a number of promising ways to contribute to the further development of the complex field of taxation related to philanthropic activities, and we hope that they build solid foundations for further studies on this topic.

Giedre Lideikyte Huber and Henry Peter

\section{Notes}

1 L. Ventura, Le "società benefit" nel mondo: Un'analisi comparata, in Societa' Benefit: Profili giuridici ed economico-aziendali, ed. by C. Bellavite Pellegrini, R. Caruso, EGEA, Milano, 2020, 115-126.

2 This section mirrors the article authored by Pascal Saint-Amans and Henry Peter and published as a blog on the OECD forum network platform. 


\section{References}

Buijze, Renate. 'Approaches towards the application of tax incentives for cross-border philanthropy', Inter$\operatorname{tax}, 44(1), 2016$.

Hemels, Sigrid. Tax Incentives as a Creative Industries Policy Instrument, in Tax Incentives for the Creative Industries. Singapore: Springer, 2017, pp. 33-64.

Silver, Natalie, and Renate Buijze. 'Tax incentives for cross-border giving in an era of philanthropic globalization: A comparative perspective', Canadian Journal of Comparative and Contemporary Law, 6, 2020, $109-150$. 